DOI:10.24193/tras.SI2019.3

Published First Online: 2019/12/21

\section{ANALYSIS OF THE EFFECTIVENESS \\ OF THE REGIONAL INNOVATION \\ SYSTEM. A CASE STUDY \\ ON POLYETHNIC REGIONS \\ OF THE RUSSIAN FEDERATION}

\section{Svetlana PANIKAROVA}

\section{Abstract}

The scientific assessment of the quality of innovation development institutions plays an important role in the modernization of regional innovation systems. At present, the scientific tools that allow us to assess the quality of innovation development institutions are not sufficiently developed, which limits the opportunities for institutional design of the regional economy. The goal of this study is to develop a systems-based approach to assessing the effectiveness of the institutional structure of regional innovation systems, and to identify the factors that determine the quality of innovation development institutions. Functional cost analysis is the basis of the methodological approach. Results of the research showed that an increase in financing the regional innovations resulted in a positive effect only in a third of the total number of the explored regions. In other cases, activation of innovative activity did not happen. Such result is explained partially by the lack of regional innovation systems (RIS) institutions in particular regions. The results of the analysis showed that the institutional environment of the regional innovation system in polyethnic regions plays an important, but not critical role. Socio-cultural factors and informal institutions have much more significant value; they either promote or interfere with the performance of RIS functions.

Keywords: regional innovation system, institutions, effectiveness, innovation policy, polyethnic region.

\section{Svetlana PANIKAROVA}

Professor, PhD, Department of Regional Economics, Innovative Entrepreneurship and Security, Ural Federal University, Ekaterinburg, Russia E-mail: panikarova_s@mail.ru 


\section{Introduction}

The modernization of the economy, which is focused on a qualitative change in the structure and sources of long-term economic growth, inevitably involves the modernization of the institutions which determine the development of national and regional innovation systems. Problems in designing innovation system institutions are particularly acute at the regional level. This is due to a high level of socio-cultural diversity and the characteristics of the economic, social and spatial development of individual regions.

In the course of formation and implementation of innovative policy in the countries with a high level of a regional variety, it is necessary to consider all features of the regional innovation system, including institutional and socio-cultural characteristics of the region. Ignoring or undervaluing the institutional factors leads to serious problems of regional and national innovative development. The institutional characteristics of RIS of polyethnic regions of the Russian Federation were analyzed for an illustration of this thesis. Although polyethnic regions are researched in the paper, the offered methodical approach goes beyond this group of regions. This method can be applied in the countries with a high level of a regional variety (including geographical, economic, social, etc.) to the justification of innovation policy tools.

The innovation systems of Russian polyethnic regions have been selected as the objects of the study in accordance with the following reasons:

a) Polyethnic regions of Russia are more independent in justification of regional innovation policy than other regions thanks to the special subfederal status (republic or autonomous region).

b) Polyethnic regions demonstrate a high level of differentiation in innovative development despite relatively equal initial socio-economic parameters, which allows for a thorough study of the reasons for such deceleration, especially in the field of the institutional support of innovation policy.

The polyethnicity of the economic space is a historical feature of Russia, where representatives of more than 100 nationalities and ethnic groups reside in a vast territory. 29 of the 85 regions of the Russian Federation are polyethnic. In some cases, they have the special status of a national-territorial entity (autonomous region or republic). In others, the share of ethnic Russians living in these regions is less than $70 \%$ of the total population.

Many publications have been devoted to assessing the innovation potential, innovation development and innovation climate in the regions of Russia. Currently, there are various systems of assessment for the innovation development of subjects of the Russian Federation, which are aimed at identifying the leaders of innovation development in Russia.

Table 1 presents the positions of polyethnic regions in three ratings at the end of 2016: Association of the Innovative Regions of Russia (AIRR), Higher School of Economics (HSE), and National Association of Innovation and Information Technology Development (NAIITD). In the presented assessment systems (ratings), the approach 
of European innovation surveys (the European Innovation Survey, the Regional Innovation Survey and the Union Innovation Survey) is used as a starting point. Rosstat data is used as the initial information base for the regions of Russia.

Table 1: Polyethnic regions in innovation development ratings (rank among the regions of Russia)

\begin{tabular}{clccc}
\hline No. & Subject of the federation & HSE & AIRR & NAIITD \\
\hline 1 & 2 & 3 & 4 & 5 \\
\hline 1 & Tatarstan & 2 & 3 & 2 \\
\hline 2 & Bashkortostan & 20 & 16 & 11 \\
\hline 3 & Ulyanovsk region & 11 & 12 & 27 \\
\hline 4 & Chuvashia & 5 & 18 & 37 \\
\hline 5 & Mordovia & 17 & 20 & 28 \\
\hline 6 & Tyumen region & 18 & 40 & 10 \\
\hline 7 & Republic of Crimea & - & - & 30 \\
\hline 8 & Khanty-Mansi Autonomous Area & 32 & 68 & 26 \\
\hline 9 & Komi & 36 & 48 & 52 \\
\hline 10 & Yamalo-Nenets Autonomous Area & 34 & 77 & 38 \\
\hline 11 & Astrakhan region & 49 & 61 & 44 \\
\hline 12 & Udmurtia & 67 & 38 & 47 \\
\hline 13 & Mari El & 57 & 31 & 70 \\
\hline 14 & Buryatia & 48 & 52 & 72 \\
\hline 15 & Adygea & 66 & 47 & 67 \\
\hline 16 & Sakha & 55 & 65 & 63 \\
\hline 17 & Karelia & 68 & 63 & 58 \\
\hline 18 & Altai & 56 & 75 & 62 \\
\hline 19 & North Ossetia - Alania & 64 & 70 & 64 \\
\hline 20 & Kabardino-Balkaria & 69 & 64 & 78 \\
\hline 21 & Dagestan & 72 & 67 & 77 \\
\hline 22 & Tyva & 74 & 80 & 68 \\
\hline 23 & Khakassia & 71 & 73 & 81 \\
\hline 24 & Chukotka Autonomous Area & 75 & 72 & 80 \\
\hline 25 & Kalmykia & 78 & 76 & 75 \\
\hline 26 & Karachay-Cherkessia & 81 & 78 & 79 \\
\hline 27 & Chechen Republic & 82 & 83 & 73 \\
\hline 28 & Nenets Autonomous Area & 79 & 81 & 85 \\
\hline 29 & Ingushetia & 83 & 82 & 84 \\
\hline & & & \\
\hline
\end{tabular}

Table 1 shows that the positions of polyethnic regions in various ratings differ quite significantly. This especially applies to regions like the Republic of Chuvashia (ranked 5 in the HSE rating but only 37 in the NAIITD rating), Tyumen region (ranked 10 in the NAIITD rating and 40 in the AIRR rating), the Khanty-Mansi Autonomous Area (ranked 26 in the NAIITD rating and 68 in the AIRR rating) and the Yamalo-Nenets Autonomous Area (ranked 34 in the HSE rating and 77 in the AIRR rating). Researchers are unanimous regarding the regions of Siberia, the Far East and the North Caucasus. These regions occupy the lowest positions in all presented ratings. 
According to the results of the integrated assessments, polyethnic regions, with a few exceptions, are mostly falling behind in innovation development. Only 8 of the 29 regions rank in the first half of the rating; the rest noticeably lag behind the average Russian values.

Therefore, study and assessment of the effectiveness of the functioning of the innovation development institutions in polyethnic regions is of great importance in the modernization of regional innovation systems, and the formation of adequate state policy tools to stimulate innovation development and qualitative economic growth.

The goal of this study is to develop a systems-based approach to assessing the effectiveness of the institutional structure of regional innovation systems based on a functional cost analysis of innovation development institutions, as well as to identify the factors which determine the quality of regional innovation institutions.

This goal is relevant due to the insufficient development of the scientific tools which allow us to assess the quality of innovation development institutions and identify existing institutional dysfunctions, traps, atrophies and degenerations emerging in the process of innovation. Their development is caused by the formation of the institutional environment and the specifics of the regional socio-economic system, which limits opportunities for institutional design in the regional economy.

The study consists of several parts. The first part provides an overview of existing approaches to understanding the institutional nature of regional innovation systems (RIS), and describes the economic categories used in the study. The second part describes the methods and techniques of the study. The third part is an evaluation of the author's approach to assessing the effectiveness of RIS institutions. The fourth part is devoted to the analysis of shortfalls in the institutional environment of regional innovation systems of polyethnic regions in Russia. The final part contains conclusions and recommendations on the adjustment of innovation policy in the studied regions.

\section{Literature review}

The concept of an 'innovation system' was first used by Lundvall in 1985 (Lundvall, 1985). Later, the idea of a national innovation system was developed in the works of acclaimed scientists (Furman et al., 2002; Boschma and Lambooy, 2002; Lundvall, 2007). In addition, the concept of a sectoral innovation system (Breschi and Malerba, 1996; Malerba, 2004) and the concept of local/regional innovation systems (Cooke, 1992; Cooke, Uranga and Etxebarria, 1997; Isaksen, 2001; Cooke and Memedovic, 2003; Iammarino, 2005) were introduced.

Scientists use different approaches to define the concept of a 'regional innovation system'. Cooke (1992) emphasizes that the essence of identifying the 'regional innovation system' category is the ability to lay the foundation for an extended discussion about the financial possibilities to stimulate innovation and to institutionalize education and a culture of innovative production in the region. Nelson (1993) defined a regional innovation system as a system which includes a set of regulators and practices which ensure the production of innovations. 
According to Cooke (2013), the regional innovation system includes two sub-systems: (a) a subsystem for the application and use of knowledge, represented mainly by commercial firms; and (b) a subsystem of knowledge generation and diffusion, which includes non-profit organizations as a general rule (mainly, the education sector and academia). Leydesdorff and Strand (2013) distinguish three functions of national and regional innovation systems: (a) the achievement of economic growth, (b) the production of technological innovations, and (c) the state regulation of the scientific and technical progress. Doloreux (2002) stresses the importance of the availability of innovative energy in the region (provided mainly by knowledge-generating enterprises and organizations), and emphasizes an important ability of the regional authorities' system - to promote and support interactions between organizations involved in the innovation cycle. Some researchers propose defining a regional innovation system as an interactive, dynamic structure that provides cooperation in regional production (Lambooy, 2002; 2004) or even as a complex of adaptable systems (Cilliers, 1998; Pavard and Dugdale, 2006).

The author defines a regional innovation system as a set of organizations and institutions whose main functions are the generation, commercialization and introduction of knowledge into the region's economy.

The core of the regional innovation system is formed by scientific and educational organizations, innovative business and regional and municipal authorities providing the implementation of scientific and technical policies, as well as regional innovation institutions which set the rules, norms and mechanisms by which they function, and that ensure the implementation of research and development work.

In a broad sense, the term 'institutions' refers to the formal and informal rules of a society which define relationships between people (Veblen, 1898). In a narrow sense, this term refers to organizational units and procedures (Commons, 1924). Institutions make up the main part of the social capital - a key factor in economic growth. The main function of institutions is to structure relationships between economic entities. The institutional structure consists of a set of institutions. The institutional structure is closely connected to the institutional environment, which consists of system-forming rules.

In accordance with the terminology developed by North and Davis, the institutional environment is a set of fundamental political, social and legal ground rules that establish the basis for production, exchange and distribution (North, 1997). The institutions of a regional innovation system perform the following functions: (1) regulation of innovation activity, (2) financing innovation activity, (3) organizational support for the transfer and diffusion of innovations, (4) stimulation of innovation activity, and (5) information support of innovation activity.

The institutional environment of regional innovation systems in polyethnic regions is strongly influenced by socio-cultural factors. Studies indicate that basic cultural values affect not only the economic development, health, lifespan, well-being and happiness of the population, but also the ingenuity and innovative dispositions of 
the individual (Inglehart and Baker, 2000; Diener, 2000; Triandis, 1994; Shane, 1995). Studies conducted in the USA (Shane, 1992) show that individualistic and non-hierarchical ('horizontal') societies are more resourceful and prone to innovation. Another international study found that originality and innovativeness depend on the socio-cultural context (Kharkhurin and Motalleebi, 2008).

Institutional factors, i.e., cultural, political and social characteristics, are more significant in polyethnic regions. Innovation is introduced faster when it is combined with these factors, and it is introduced more slowly or not at all when they are incompatible. Thus, Klimanov and Bylov conducted a spatial-temporal analysis of the spread of market institutions in Russian regions in the 1990s. The results of the analysis showed that most republics were outsiders in this regard (Klimanov and Belov, 1997). Based on the analysis of cultural values and attitudes towards innovations in various regions of the Russian Federation, Lebedeva and Yasin substantiated the idea that Russia's innovative weakness was largely due to the specific features of the culture and social institutions of 'ethnic' regions. Neglecting these features during the implementation of innovation policy has hindered the spread of innovation in Russia (Yasin and Lebedeva, 2009). Pilyasov believes that if these features are taken into account, outsider regions can become leaders in innovative development because cultural and ethnic differences, intellectual differences and openness to the outside world stimulate the innovation process (Pilyasov, 2009).

The polyethnic regions of the Russian Federation have, for the most part, lower levels of innovation development. Development trends in the economic space of the Russian Federation suggest that this level will decrease in the future. In this regard, it is necessary to study not only the economic and geographical factors, but also the institutional factors behind the innovation level gap of polyethnic regions.

A number of academics have recently attempted to assess the effectiveness of regional innovation system institutions (Buesa et al., 2006; Chen and Guan, 2012; D’Allura et al., 2012). Stejskal et al. (2018) suggested the method of assessing regional innovation systems based on the assessment of qualitative and quantitative indicators using WSA methods (Weighted Sum Approach Methods). De Marchi and Grandinetti (2017) conducted a quantitative assessment of the effectiveness of regional innovation systems in Italy using statistical data. The author considers the interconnection of the innovation system's elements as the main criterion of RIS effectiveness. Leydesdorff and Porto-Gomez (2017) consider the synergistic effect of innovation as the main criterion of the effectiveness of RIS institutions: these scholars used geographic, technological and organizational parameters to analyze the institutional structure of RIS in Spain.

Despite the interest in the study of RIS effectiveness, economic science still has no unified methodological approach to analyzing the formation and functioning of the innovation development institutions, and assessing their effectiveness. At the same time, analysis of institutions and institutional structures which ensure the functioning of regional innovation systems will lead to a different qualitative level of studying the processes involved in financing research activities in the regions. Development of 
a RIS analysis methodology will provide an opportunity to formalize the conditions contributing to the increase in the management efficiency of knowledge generation processes, and the development of the regional innovation systems as a whole.

The rapid development of institutional theory greatly enriches the methodological tools of economic studies. However, the institutional analysis is of qualitative nature in most studies. In addition, there is still no consensus among institutionalists on the criteria to measure an institution's effectiveness. The development of quantitative analytical tools for assessing the effectiveness of innovation development institutions, and identifying institutional dysfunctions in the regional innovation system will provide a scientific information base for decision makers in the field of regional economic and innovation development.

\section{Methods of study}

The methods and approaches used for solving the present research problems are based on the theoretical and methodological instruments of regional economy, as well as institutional and economic-mathematical analysis. The methodological instruments of regional economy include well-known methods such as integrated assessments and ratings. The methodological instruments of institutional analysis include the systematization of institutions, and the author's developments in assessing institutional dysfunctions. Furthermore, correlation analysis was also used.

The research included three stages. At the first stage, the assessment of the efficiency of a regional innovation system was carried out. At the second and third stages, the reasons for insufficient efficiency of RIS and the lack of institutional support for innovative activity were analyzed.

The first stage of the study consists of the approbation of the author's methodical approach to analyzing the effectiveness of innovation development institutions. This approach is based on the assumption that a change in innovation development costs proportionally changes the results of innovation activity in the region if the RIS institutions function effectively. The data source is the official regional statistics. The values of the volume of innovative goods and services were used as variables characterizing the results of the innovation system. The values of the internal research and development costs were used as variables characterizing the costs of the creation and operation of innovation institutions. Correlation and functional cost analysis were used as methodical tools.

In the second stage, the analysis of the institutional environment for innovation activity was carried out based on the criterion of the presence of development institutions performing essential functions of RIS. The author analyzed data from the official websites of regional authorities and the website for innovation and business support 'Innovation and entrepreneurship'; on this portal, a summary of the registered organizations of the Russian Federation contributing to innovative development is provided.

In the third stage, the institutional capacity of regional innovation policy was analyzed. The information base consisted of the websites of regional authorities and data 
from the Institute for Statistical Studies and Economics of Knowledge at the National Research University Higher School of Economics.

\section{Main results of the study}

\subsection{Assessment of the effectiveness of RIS institutions}

The author uses a functional approach to assess the effectiveness of RIS institutions and to analyze the quality of RIS. The analysis aimed to assess:

1. The extent to which the institution performs its main functions, i.e. achieving performance/efficiency targets; and

2. The ratio of the innovation financing volume and the parameters characterizing these functions in the studied RIS.

In economics, innovation is 'the end result of innovation activity, embodied by a new or improved product introduced to the market; a new or improved technological process used in practical activities' (Hobday, 2005). Innovation activity involves a whole range of scientific, technological, organizational, financial and commercial events, which together lead to innovation. Therefore, it can be assumed that each monetary unit invested in R\&D in an effective RIS not only pays off, but also multiplies in the form of an innovative product sold on the market. Therefore, the effectiveness of RIS should be assessed by a direct dependence between the parameters of innovation financing and the parameters of innovation effectiveness. Correlation analysis is one of the methods which can confirm or disprove the existence of a link between the two variables.

In order to assess the quality of innovation development institutions, the author conducted an analysis of the correlation dependencies between the series of values of innovation development costs and the series of values of innovation activity indicators in Russian polyethnic regions for the period 2004-2016. Further conclusions about the quality of RIS institutions were based on the following assumptions:

- If the value of the correlation coefficient is less than -0.5, i.e. there is a medium/ high negative correlation, then there is an institutional trap. In institutional theory, an institutional trap is an inefficient sustainable norm (an inefficient institution) of a self-sustaining nature;

- If the value of the correlation coefficient is between -0.49 and 0.49 , then this is an institutional dysfunction - a disruption of the functions of an economic institution for innovation development, mainly of a qualitative nature;

- If the value of the correlation coefficient is between 0.5 and 0.69 , then the institution for innovation development is not effective, or the institution is at the formation (development) stage;

- If the value of the correlation coefficient is more than 0.7 , then the institution is effective.

The study took into account the regional variation of the innovation cycle, which includes several stages: fundamental research, exploratory research, applied research, 
development, production mastering, implementation, and spread. The duration of the innovation cycle and its individual stages depend on a variety of factors determined by the characteristics of its socio-economic environment. Therefore, the author assumed that the optimal average duration of the innovation process is different in various regions. Therefore, the correlation analysis was carried out taking into account the time lags of 1-5 years.

The author used official regional statistics on R\&D costs and innovation activity performance indicators in the period 2004-2016 as data sources. The correlation coefficients between the indicators were calculated taking into account the time lags, since the duration of the innovation cycle in different regions varies (depending mainly on the structure of the economy) (Table 2).

Thus, the high quality of RIS institutions is typical for the following regions: the Republic of Tatarstan, the Republic of Bashkortostan, Ulyanovsk region, the Chuvash Republic, the Republic of Mordovia and Tyumen region (i.e., regions which occupy the top positions in all the ratings). The Republic of Adygea is the exception in the group of regions with high-quality institutions: innovation development institutions in the region perform their functions effectively despite a low rating. A high level of institutional efficiency is also noted in the innovation systems of regions like the Yamalo-Nenets Autonomous Area, the Astrakhan region, Udmurtia and Karelia. However, the duration of the innovation cycle in these regions is 4-5 years due to the structural features of their economies.

Regional innovation systems with developing institutions are typical for the following regions: the Komi Republic, the Sakha Republic and the Republic of Buryatia. The listed regions take middle positions in the ratings of innovative development of the Russian Federation. RIS institutions of these regions with identical probability can both pass into the category 'effective', and become dysfunctional over time.

Institutional traps in regional innovation systems were identified in the Republics of Dagestan, Ingushetia, Kabardino-Balkaria and North Ossetia, and in the Chukotka Autonomous Area. In these regions, the effectiveness of innovation activity decreases with increasing $R \& D$ funding. A thorough analysis of each of the listed regions is required to identify the reasons for such a serious violation of RIS activities.

The innovative systems of the remaining polyethnic regions are dysfunctional, i.e. the innovation institutions do not perform the functions for which they were created. Consequently, an increase in R\&D funding in these regions will not have the expected effect until a detailed review of the entire institutional infrastructure for innovation activity takes place. 


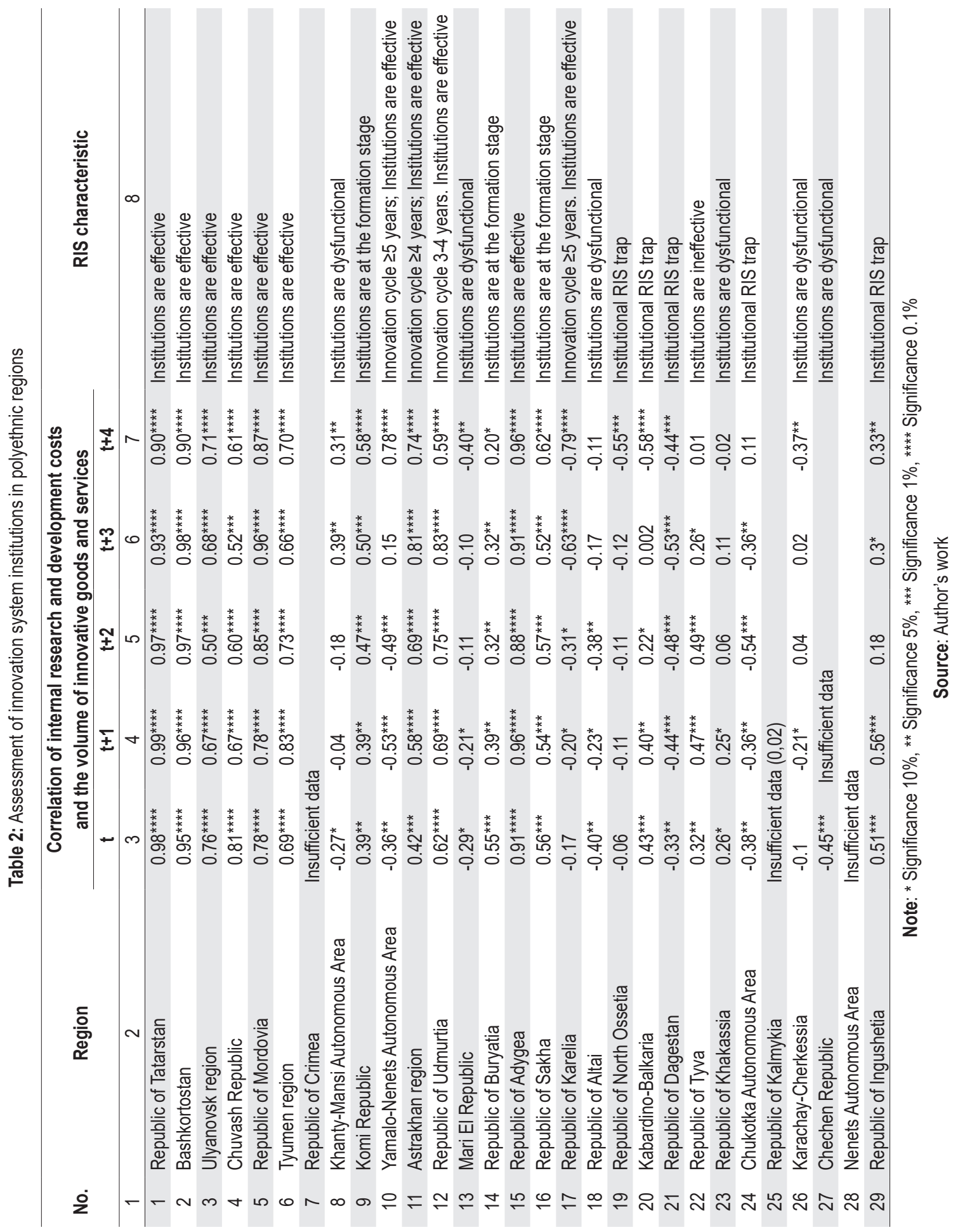




\section{Analysis of shortfalls in the institutional environment of regional innovation system}

Assessment of the effectiveness of RIS institutions showed that from 29 studied regions only ten regions have RIS with institutions that effectively perform the functions on institutional supporting innovative activity, RIS institutions of three regions are at a development stage, and RIS institutions of other regions are dysfunctional or institutional traps.

With the purpose to find out the inefficiency reasons of RIS, the existence and the number of institutions performing the RIS separate functions in each region were investigated. For this research, the RIS institutions presented in Table 3 were considered.

Table 3: Institutions in the regional innovation system

\begin{tabular}{ll}
\hline \multicolumn{1}{c}{ Function of RIS } & \multicolumn{1}{c}{ Institutions } \\
\hline Regulation of innovation activity & - Innovation activity coordination authorities \\
Financing innovation activity & - R\&D financing funds; and \\
& - Venture funds \\
Stimulation of innovation activity & - Business incubators; \\
& - Technological incubators; and \\
Organizational support of transfer & - Technology parks \\
and diffusion of innovations & - Innovation and technology centers; and \\
Information support of innovation activity & - Technology transfer centers \\
\hline
\end{tabular}

Source: Author's work

Afterwards, the institutional support of regional innovation policy was analyzed in each region. The analysis was based on the criterion of the presence of the most important elements of institutional environment such as: (1) a strategy of innovation development in the region (or the profile section in the strategy of regional development); (2) specialized legislation defining the principles, directions and measures of state support for innovation activities in the region; (3) a program or a set of state support measures aimed at the development of innovation in the region; (4) the availability of specialized innovation policy coordinating authorities; and (5) regional innovative fund for the financing of innovative activity.

The results of the conducted research are presented in Table 4. The results of the analysis of the institutional capacity of the innovation activities in Russian polyethnic regions (columns 3-7 of Table 4) show that the leaders of innovation development among the studied regions have not experienced a shortage of the institutions that perform RIS functions. A high level of institutional support for innovation activity has been observed in such regions as the Republic of Tatarstan, the Republic of Bashkortostan, the Chuvash Republic, the Republic of Mordovia and Tyumen region.

The main problems of the development of RIS in the Komi Republic lie in the formation of regional innovation policy: it is necessary to develop regional programs to 


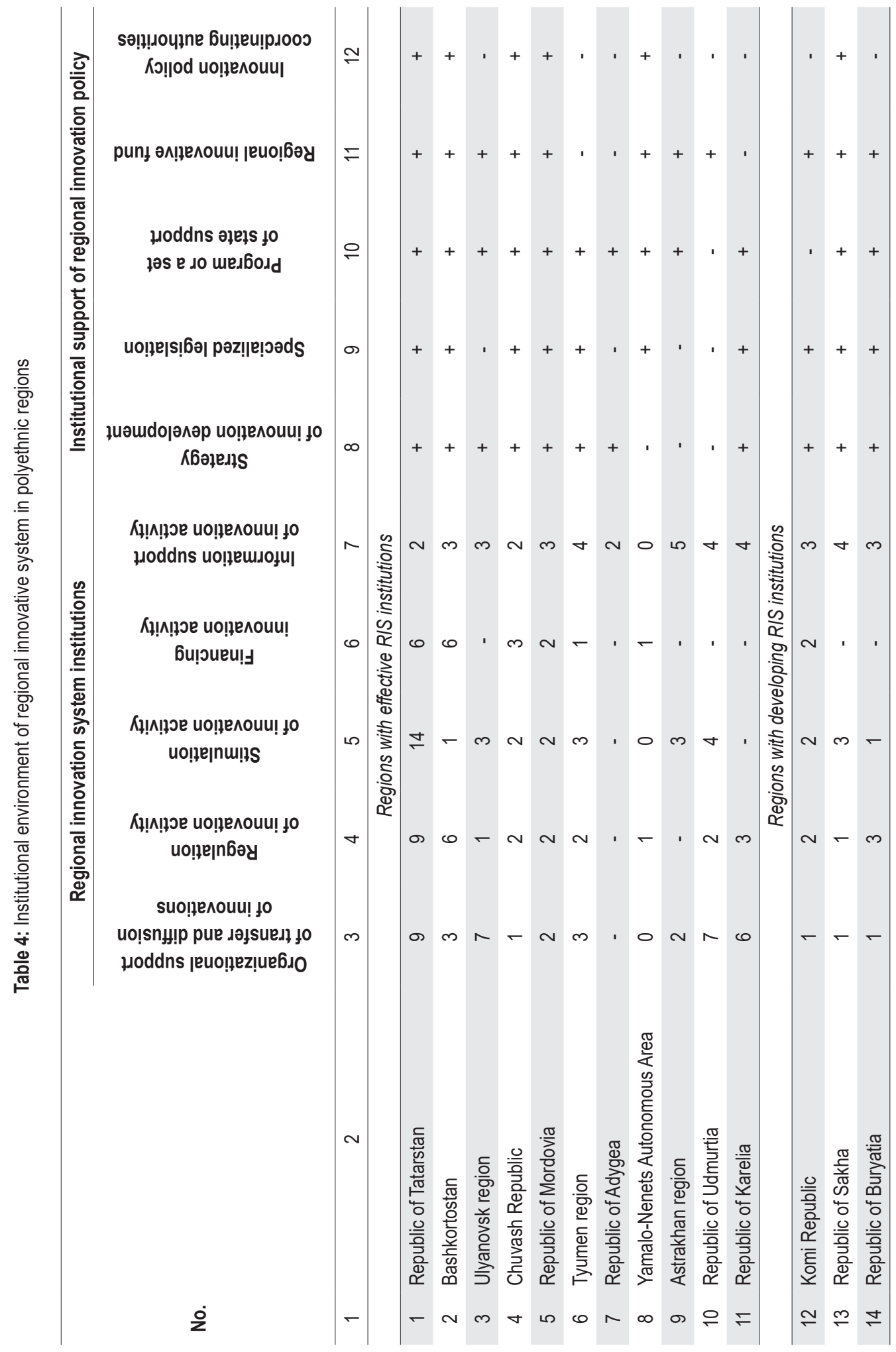




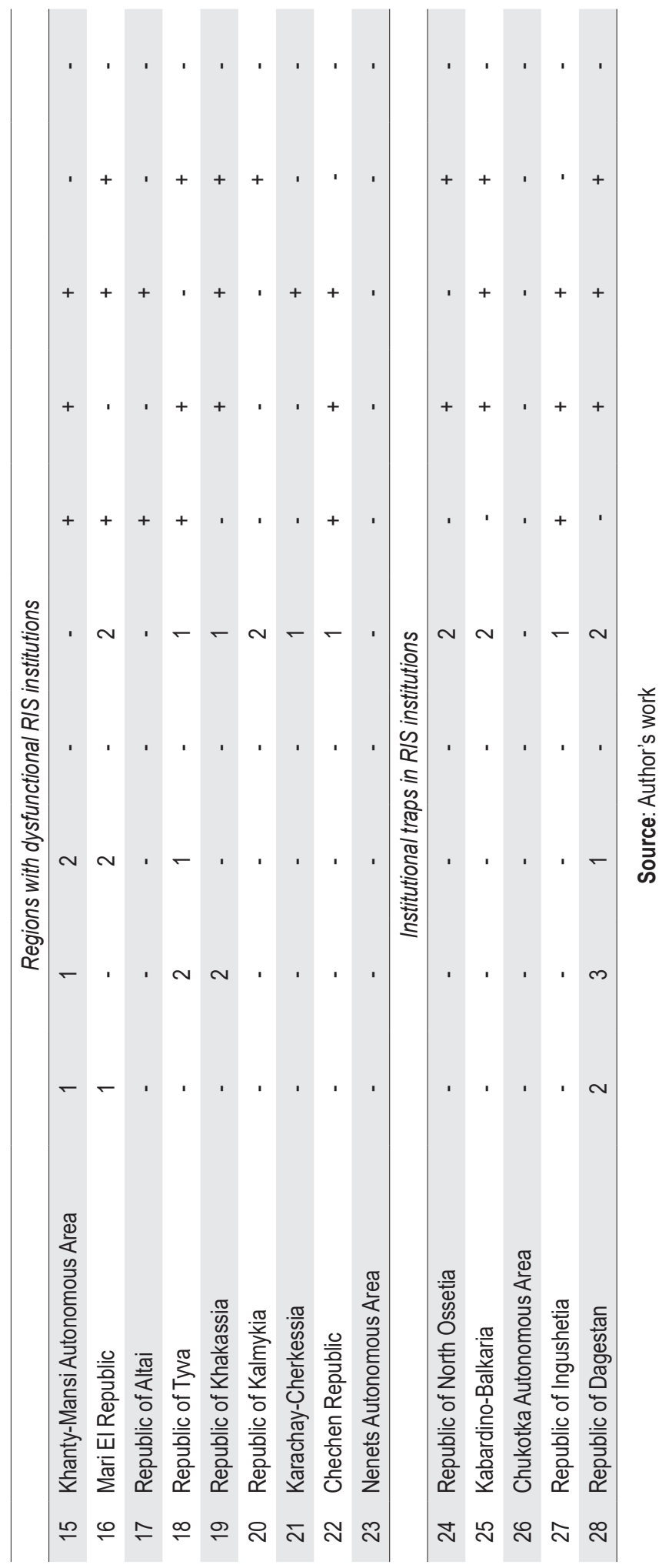


support and finance innovation activities. The republics of Buryatia and Sakha lack the RIS institutions which perform financing functions.

At the same time, a lack of specialized regional institutions for innovation development was identified in most polyethnic regions of the Russian Federation. Engineering and technology centers, technology transfer centers, innovation activity coordination authorities, technology parks and business incubators are absent in 12 of the 29 regions. There is a lack of venture funds and financial companies focused on innovative business in 20 regions.

An extremely low level of institutional support for innovation activities was observed in regions like the Chukotka Autonomous Area, the Republic of Kalmykia, the Karachay-Cherkess Republic, the Chechen Republic, the Nenets Autonomous Area, the Republic of Ingushetia, the Republic of Altai, the Republic of North Ossetia-Alania and the Kabardino-Balkaria Republic. As a result, these regions have fallen significantly behind the leaders in terms of the effectiveness of RIS institutions.

Thus, the analysis of institutional capacity has shown that it is necessary to have all the elements of an institutional RIS subsystem (performing the functions of regulating, financing, organizing, stimulating and informing) for the innovation development of a region. The aforementioned specialized regional institutions for innovation development play an essential role in shaping an institutional structure conducive to the development of innovations in polyethnic regions. At the same time, the effectiveness of these institutions is partly determined by the quality of regional innovation policy, and its institutional component in particular.

The results of the analysis of institutions providing innovative policy (columns 8-12 of Table 4) showed that the following polyethnic regions have the best institutional support for innovation policy: Republic of Tatarstan, Republic of Bashkortostan, Republic of Yakutia (Sakha), Chuvash Republic and Republic of Mordovia. It should be noted that these regions have a high efficiency of RIS institutions. In contrast, regions with underdeveloped innovation policy institutions occupy lower positions: Chukotka Autonomous Area, Karachay-Cherkess Republic, Nenets Autonomous Area, Republic of Kalmykia, Republic of North Ossetia-Alania, and Republic of Altai.

Thus, the presence of institutions performing these functions promotes but does not guarantee that the regional innovation system achieves high indicators of effectiveness and efficiency (for example, Republic of Dagestan has low RIS efficiency, despite rather high support for innovative institutions). Also, on the contrary, RIS institutions can be effective in the absence of enough formal institutions for innovative development (for example, Republic of Adygea). According to the author, the main reason for this phenomenon are the disparities and contradictions in the interaction of formal and informal institutions. The scientific literature describes the following ways in which informal institutions can affect the effectiveness of formal ones: (1) an informal institution can lead to an increase in the efficiency of a formal one with the help of a 'complement effect (complementarity)' and an 'accommodation effect (adaptation)'; and (2) an informal institution can lead to a decrease in the efficiency of a 
formal institution due to a 'substitution effect' and a 'competition effect' (Helmke and Levitsky, 2004).

The competition between clan protectionism and innovation development institutions in the Republics of South Siberia (Tyva, Khakassia and Altai) and the North Caucasus (Dagestan, Ingushetia, Kabardino-Balkaria, North Ossetia, etc.) is an example of the negative impact of informal institutions on innovation development. Informal social regulation based on kinship, solidarity, trust and mutual assistance is much more developed in these regions. There are no 'career elevators' outside the clan; social and generational hierarchies within the clan are very strong. The most promising areas of commercial activity are monopolized by the ruling elites at republic and district levels. As a result, innovators do not have access to the resources of innovation development institutions.

At the same time, the informal institutions of polyethnic regions can stimulate innovation activity. For example, the interaction of informal institutions of ethnic solidarity and formal institutions of the network economy ${ }^{1}$ in the Volga republics (Tatarstan, Bashkortostan, Chuvashia and Mordovia) has led to the 'complement effect'. This increases the effectiveness of formal institutions for innovation development.

\section{Conclusions}

The author offered a method of economic efficiency assessment for RIS institutions, which allowed to reveal qualitative and dysfunctional institutions and also institutional traps of innovative development of the Russian polyethnic regions. Regional authorities can apply this method for the justification of financial mechanisms for stimulation of innovative activity in regions.

The results of the research showed that the increase in financing regional innovations resulted in a positive effect only in a third of the total number of the explored regions. In other cases, activation of innovative activity does not happen. Partially, such a result is explained by a lack of RIS institutions of particular regions.

Research of RIS institutional environment allowed to conclude that the lack or absence of institutions on one and more RIS functions naturally lead to a decrease in efficiency of the entire system. Based on the results of the analysis, it is also possible to conclude that institutions providing innovative policies play an important, but not critical role. Socio-cultural factors and informal institutions have much more significant value; they either promote or interfere with the performance of RIS functions.

1 A network economy is an economic system based on the interconnection of three elements: social (economic) networks; the technological specifics of the post-industrial lifestyle; and the institutional specifics of the post-industrial economy (computer technologies, international trade, entertainment and tourism, real estate management and the cultural and creative industries). Trust based on shared ethnic identity forms 'ethnic' social (economic) networks and reduces potential transaction costs associated with distrust (for example, the use of intermediaries acting as guarantors in business becomes redundant). 
The results of the study suggest that most polyethnic regions face a common problem: a low level of institutional capacity in innovation development associated with a lack of the necessary 'bridges', norms and rules for connecting disparate innovation system organizations. This problem must be solved during regional innovation development. The problem is also aggravated by the fact that the innovation development institutions, which function effectively in most parts of the country, often cease to perform their functions in polyethnic regions.

In summary, the author identifies several main directions of regional policy aimed at increasing the effectiveness of innovation development institutions in the studied regions:

1. Initiation of researches on actors' economic innovative behavior, taking into account the action of informal institutions and socio-cultural factors;

2. Formation of new financing mechanisms for innovative projects, which consider socio-cultural features of regions;

3. Implementation of large-scale infrastructure projects designed to link large enterprises, small businesses, scientific organizations and universities;

4. Development of institutional support for innovation policy; and

5. Development of the informational, expert-consulting and educational infrastructure of innovation activity.

\section{References:}

1. Boschma, R.A. and Lambooy, J.G., 'Knowledge, Market Structure and Economic Coordination: Dynamics of Industrial Districts', 2002, Growth and Change, vol. 33, no. 3, pp. 291-311.

2. Breschi, S. and Malerba, F., 'Sectoral Innovation Systems: Technological Regimes, Schumpeterian Dynamics and Spatial Boundaries', in Edquist, C. (ed.), Systems of Innovation: Technologies, Institutions, and Organizations, London: Pinter, 1997, pp. 130-156.

3. Buesa, M., Heijs, J., Martínez Pellitero, M. and Baumert, T., 'Regional Systems of Innovation and the Knowledge Production Function: The Spanish Case', 2006, Technovation, vol. 26, no. 4, pp. 463-472.

4. Chen, K. and Guan, J., 'Measuring the Efficiency of China's Regional Innovation Systems: Application of Network Data Envelopment Analysis (DEA)', 2012, Regional Studies, vol. 46, no. 3, pp. 355-377.

5. Cilliers, P., Complexity and Postmodernism: Understanding Complex Systems, New York: Routledge, 1998.

6. Commons, J., The Legal Foundations of Capitalism, New York: McMillan, 1924 (reprint Madison: University of Wisconsin Press, 1968).

7. Cooke, P., Complex Adaptive Innovation Systems: Relatedness and Transversality in the Evolving Region, New York: Routledge, 2013.

8. Cooke, P., 'Regional Innovation Systems: Competitive Regulation in the New Europe', 1992, Geoforum, vol. 23, no. 3, pp. 365-382.

9. Cooke, P. and Memedovic, O., Strategies for Regional Innovation Systems: Learning Transfer and Application, Vienna: Strategic Research and Economics Branch, United Nations Industrial Development Organization (UNIDO), 2003, pp. 1-38. 
10. Cooke, P., Uranga, M. and Etxebarria, G., 'Regional Innovation Systems: Institutional and Organizational Dimensions', 1997, Research Policy, vol. 26, no. 4-5, pp. 475-491.

11. D’Allura, G.M., Galvagno, M. and Mocciaro Li Destri, A., 'Regional Innovation Systems: A Literature Review', 2012, Business Systems Review, vol. 1, no. 1, pp. 139-156.

12. De Marchi, V. and Grandinetti, R., 'Regional Innovation Systems or Innovative Regions? Evidence from Italy', 2017, Tijdschrift voor Economische en Sociale Geografie, vol. 108, no. 2, pp. 234-249.

13. Diener, E., 'Subjective Well-being: The Science of Happiness, and a Proposal for a National Index', 2000, American Psychologist, vol. 55, no. 1, pp. 34-43.

14. Doloreux, D., 'What We Should Know about Regional Systems of Innovation', 2002, Technology in Society, vol. 24, no. 3, pp. 243-263.

15. Furman, J., Porter, M. and Stern, S., 'The Determinants of National Innovative Capacity', 2002, Research Policy, vol. 31, no. 6, pp. 899-933.

16. Helmke, G. and Levitsky, S., 'Informal Institutions and Comparative Politics: A Research Agenda', 2004, Perspectives on Politics, vol. 2, no. 4, pp. 725-740.

17. Hobday, M., 'Firm-level Innovation Models: Perspectives on Research in Developed and Developing Countries', 2005, Technology Analysis \& Strategic Management, vol. 17, no. 2, pp. 121-146.

18. Iammarino, S., 'An Evolutionary Integrated View of Regional Systems of Innovation: Concepts, Measures and Historical Perspectives', 2005, European Planning Studies, vol. 13, no. 4, pp. 497-519.

19. Isaksen, A., 'Building Regional Innovation Systems: Is Endogenous Industrial Development Possible in the Global Economy?', 2001, Canadian fournal of Regional Science, vol. 24, no. 1, pp. 101-120.

20. Klimanov, V.V. and Belov, G.V, 'Пространственная диффузия маркетинговых инноваций в России' (Spatial Diffusion of Market Innovations in Russia), 1997, Вестник РГНФ: Науки о человеке и обществе (RFBR Newsletter: The Science of Man and Society), no. 5, pp. 12-19.

21. Lambooy, J., 'Knowledge and Urban Economic Development: An Evolutionary Perspective', 2002, Urban Studies, vol. 39, no. 5-6, pp. 1019-1035.

22. Lambooy, J., 'The Transmission of Knowledge, Emerging Networks, and the Role of Universities: An Evolutionary Approach', 2004, European Planning Studies, vol. 12, no. 5, pp. 643-567.

23. Leydesdorff, L. and Porto-Gomez, I., 'Measuring the Expected Synergy in Spanish Regional and National Systems of Innovation', 2017, Journal of Technology Transfer, vol. 41, no. 1, pp. 189-209.

24. Lundvall, B.Å., Product Innovation and User-Producer Interaction, Aalborg: Aalborg University Press, 1985.

25. Lundvall, B.Å., 'National Innovation Systems - Analytical Concept and Development Tool', 2007, Industry and Innovation, vol. 14, no. 1, pp. 95-119.

26. Malerba, F., Sectoral Systems of Innovation: Concepts, Issues and Analysis of Six Major Sectors in Europe, Cambridge: Cambridge University Press, 2004.

27. Nelson, R.R., National Innovation Systems: A Comparative Analysis, Oxford: Oxford University Press, 1993. 
28. North, D., 'Институциональные изменения: рамки анализа' (Institutional Changes: Framework for Analysis), 1997, Вопросы экономики (Voprosy Ekonomiki (Issues of the Economy)), no. 3, pp. 6-17.

29. Pavard, B. and Dugdale, J., 'The Contribution of Complexity Theory to the Study of Socio-technical Cooperative Systems', in Minai, A.A. and Bar-Yam, Y. (eds.), Unifying Themes in Complex Systems, Berlin: Heidelberg, 2006, pp. 39-48.

30. Pilyasov, A.N., И последние станут первыми. Северная периферия на пути к экономике знания (And the Last Shall Be the First: The Northern Periphery on the Road to the Knowledge Economy), Moscow: LIBRIKOM, 2009.

31. Rosstat, Russian Statistical Yearbook, Moscow: Rosstat, 2017.

32. Shane, S., Venkatarman, S. and MacMillan, I., 'Cultural Differences in Innovation Championing Strategies', 1995, Journal of Management, vol. 21, no. 5, pp. 931-952.

33. Shane, S., 'Why Do Some Societies Invent More Than Others', 1992, fournal of Business Venturing, vol. 7, no. 1, pp. 29-46.

34. Leydesdorff, L. and Strand, D., 'The Swedish System of Innovation: Regional Synergies in a Knowledge-based Economy', 2013, Journal of the American Society for Information Science and Technology, vol. 64, no. 9, pp.1890-1902.

35. Stejskal, J., Kuvíková, H. and Meričková, B.M., 'Regional Innovation Systems Analysis and Evaluation: The Case of the Czech Republic', in Stejskal, J., Hajek, P. and Hudec, O., Knowledge Spillovers in Regional Innovation Systems, Cham, Switzerland: Springer International Publishing, 2018, pp. 81-113.

36. Triandis, H.C., Culture and Social Behavior, New York: McGraw-Hill, 1994.

37. Veblen, T., 'Why Is Economics Not an Evolutionary Science', 1898, Quarterly fournal of Economics, vol. 12, no. 4, pp. 373-397.

38. Yasin, E.G. and Lebedeva, N.M., 'Культура и инновации: к постановке проблемы’ (Culture and Innovation: Problem Statement), 2009, Форсайm (Foresight), vol. 3, no. 2, pp. 1626. 